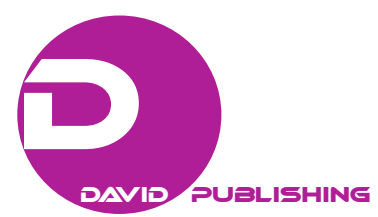

\title{
Post-2015 Development Priorities for the Arab World
}

\author{
Ibrahim Elnur \\ The American University in Cairo, New Cairo, Egypt \\ Eileen Kuttab \\ Birzeit University, Birzeit, Palestine
}

\begin{abstract}
The paper addresses the failure of renewing the same millennium development goals (MDGs) format in measuring achievement in a region like the Middle East and North Africa (MENA) region which is drastically being transformed. A new approach focusing on "human security" principles based on freedom, dignity, justice, equality, solidarity, tolerance, and respect articulated in the millennium declaration is needed. Achieving this requires a more integrated, inclusive, and comprehensive development framework that is able to analyze and understand the context with its progress and setbacks. The paper realizes that measuring MDGs achievement does not only need a comprehensive integrated approach, but also a definition of risks and challenges that the region faces. Issues like poverty, inequality, unemployment of graduates, personal and collective insecurity due to conflict, migration, and brain drain, food insecurity, and gender inequality are all issues that need to be redefined when analyzing the region to suit the context. The paper concludes that in order to understand the context, re-definition of concepts like poverty reduction, participation, and empowerment is needed to make concepts more relevant to the context. Lastly, the paper reflects the new call from youth for a new development model that is not based on market economy, ends political economy of the rentier states, and emphasizes a productive oriented economy that is able to generate employment and decent work. It also emphasizes democratic governance as an only path for a sustainable participatory development that can realize ambitions and aspirations of the majority of population.
\end{abstract}

Keywords: human security, poverty, gender inequality, empowerment, millennium development goals (MDGs)

\section{Introduction or Overview}

2015 marks the deadline for achieving the millennium development goals (MDGs) and it is widely recognized that simply renewing the goals in their current format will not be sufficient. A more analytical and inclusive approach is required. This could be achieved by using human security principles to underpin a post-2015 development framework that would express the values of freedom, dignity, equality, solidarity, tolerance, and respect for nature articulated in the millennium declaration. In other words, a more sophisticated and inclusive development framework that moves beyond the basic priorities outlined in the current set of goals is required. A framework with human security as its basis would ensure that:

- All areas of the current MDGs are captured in an integrated way;

Ibrahim Elnur, associate professor of development studies and political economy, chair, Department of Political Science, American University in Cairo, New Cairo, Egypt.

Eileen Kuttab, associate professor in sociology director, Institute of Women Studies, Birzeit University, Palestine.

Correspondence concerning this article should be addressed to Ibrahim Elnur, American University in Cairo, P.O. Box 74, New Cairo, 11835, Egypt. 
- Both objective human development outcomes and subjective perceptions of personal and community wellbeing are encompassed;

- The new framework leads directly into a discussion regarding joined-up policy responses, combining human and sustainable development.

The Arab region is not an isolated island, but it has been dialectically affected by the critical global and regional changes over the last decade, bearing positive, negative developments, as well as uncertainties. Although the region has achieved progress in many MDGs, yet progress in many of the MDGs is seen, significantly in health and education, while other goals have seen some progress but still experience setbacks.

Assessing the MDGs progress across the region is complex, due to sharp disparities among the different regions at the socio-economic, political, and economic levels. Moreover, different forces and challenges have affected the process of MDG performance variably. Challenges resulting from the global economic financial crisis of 2008-2009 and the Arab revolutions or wave of uprisings resulting from the erosion of structural foundation of authoritarian Arab regimes based on patronage have undermined these political structures. Corruption and the concentration of growth dividends in the hands of elite who viewed social expenditure as real investment for the future developmental regional approaches marginalizing the productive economic sectors resulting in structural poverty, unemployment, and food insecurity have all jeopardized the attainment of MDGs in a timely manner. Most important challenges are analyzed through the following issues.

\section{Development and Security Challenges}

Conflicts-related challenges represent one of the main challenges for development, as it has been further aggravated in the last four years by the events in Iraq, Syria, and more recently in Libya and Yemen. The absence of public and personal security and the persistence of violence hinder economic growth and development in a gendered way. There is a need to emphasize water security as an important component of sustainable development for a region that is likely to be impacted negatively by the global climatic changes. Furthermore, the political economy dimensions of the failed transition are increasingly impacting negatively several challenges (education, poverty, health services provision, etc.).

It is worth noting that there is no mechanical link between sustainable development and economic growth and there is a need to be reminded that no trickle down sustainable development is feasible without a mechanism of redistribution of resources and services, or intervention policies that are pro-poor which can only happen if there is a political will from democratic governments to emphasize the right for development and economic security for all. The absence of political stability and security makes economic growth difficult to attain; while at the same time, the imposition of development paradigms through financial support that do not take national priorities into consideration can also delay the achievement of MDGs especially in addressing unemployment and poverty. However, it is important to note that there can be no sustainable development in precarious conditions; hence as the Arab region is passing through very unstable insecure conditions, even some of the achievements on MDGs could have a setback.

On another level, it was also concluded based on a gender review conducted in the Arab Human Development Report 2014 (Hilal, Kuttab, \& Abdel, 2015) that the analysis has failed to reflect the political as well as the structural obstacles that resulted in the drastic deteriorating conditions of the Arab region at the social and economic level in the past five years. The intended absence or abstraction of the analysis from the 
political context has manipulated the real understanding of the causes of deterioration of overall conditions of the economic standards of living of most of the social sectors of Arab society resulting from the public and personal insecurities and conflict; the collapse of the social safety nets due to neoliberal policies and privatization of basic services; or the emergence of new forms of slavery and exploitation exemplified by "sex touristic industry", "human trafficking", and "economic exploitation" that the report describes as phenomenon within the Arab region. These are all structural obstacles towards realizing the MDGs within the region. At the same time, although the report talks about these issues as hindrances to human development, there is no mention of accountability or responsibility which resulted in lifting the blame from international as well as regional political systems and organizations that should bear the responsibility of the causes and consequences of the regional unrest and absence of solutions to the humanitarian problems. Measuring the achievements of MDGs cannot happen or be measured in vacuum, but only in relation to the reality of the political as well as the economic conditions. One can clearly say now that some of the indicators and achievements that occurred have not been kept due to the regional unrest and conflict.

\section{Poverty and Inequality}

The challenge is not just poverty but also inequality. As it has been noted earlier, it is not poverty but injustice that generated the uprising in Bahrain. In the time of compression of both time and space, all forms of inequalities became glaringly visual. One important outcome of both population growth and the political patronage package was the acceleration of the process of urbanization. The emerging new forms of "Urbanities" and "Ruralities" (Elnur, 2009) are the site for such increasing visuality. These new multi-layered urbanities are characterized by extreme levels of disparities, extending from sky-scrapers to shanty towns. At the same time, the rural is no longer the old, dormant, isolated, and remote political-social space, but rather - thanks to the nature of technological change - is marked by the compression of both time and space across income and literacy barriers (Elnur, 2009). These new multi-layered urbanities and ruralities constitute serious challenge to the capacity of the security sector, irrespective of its size, and outreach capacity. It is this visuality of inequalities that will constitute a serious challenge to viability of polices based on the limited notion of poverty reduction. The "old" patronage-based social contract seems to have lost its historical momentum (Elnur, 2013).

The national development plans have not been able to deal with unemployment as one source of poverty, due to the nature of labor market and the marginalization of the productive sectors which was further reflected in the expansion of informal sectors of the economies. This context sees more women employed in the informal sector with no social safety nets or social protection which marginalize them further and delegitimize their participation in the formal labor market.

\section{Education: The Quality and Paths to Social Mobility}

While universal education remains as a central issue, there is a need to examine carefully the available statistics and information on school attendance. Important detailed statistics on school drop-out and more importantly the quality of education are offered. Several studies suggest that a serious proportion of primary school graduate may graduate without acquiring the basic level of literacy and numeracy or even retard to a status of illiteracy (Elnur, 2004). The path towards social mobility is further undermined by subsequent developments in the educational system that led to the creation of a parallel educational universe - that of 
private education (Elnur, 2004). With private education (from pre-school to higher education) quickly emerging as the only center of excellence, the social mobility role of education was almost completely eliminated.

\section{Education: Graduate Unemployment Crisis}

Compared to other similar regions, the Arab countries' achievements in higher education enrollment are both remarkable and paradoxical. In more populated countries (Iraq, Sudan, Egypt, and Yemen), the vast expansion of higher education was not linked to universal provision of primary education. Thus, these states remained characterized by high illiteracy rates, with illiterate females representing almost twice the illiterate males in many Arab countries (UNESCO, 2010).

The vast expansion in higher education in the Arab countries created a massive body of unemployed university graduates. Graduate unemployment reached $40 \%$ in countries where reliable statistics were available (European Training Foundation, 2011; Elnur, 2011; 2012). In most of these countries, unemployed female graduates were double the figures for male graduate unemployment (European Training Foundation, 2010; World Bank, 2007).

The graduate unemployment crisis reflects several aspects of the problems of the education system as well as the rentier and quasi-rentier economies of the region. Primary among these is the declining quality of both general education as well as higher education (Ibrahim, 2000; Ammar, 1996). The mismatch between the education system output and labor market demand is evident almost everywhere, but such a mismatch cannot explain the full dimension of the graduate unemployment crisis. The supply of graduates seems well beyond the capacity of these economies to absorb, which simply confirms that the demand for higher education continues to be socially-driven. The outcome, however, of creating such a massive body of unemployed and, sadly, unemployable, young people, has been an ominous wellspring of social unrest.

The issue of graduate employment deserves a more thorough understanding that goes beyond the most visible causes (quality, mismatch, and over-production), but also it has some important elements that are not specific to the Arab countries. The demand for higher education continues to be socially driven and the complete segregation of the usually lagging behind vocational education is a phenomenon triggering similar discourses in the advanced global North. Recent studies in this phenomenon were considering the potential for "vocationalization" of the higher education.

At the same time, the dialectic mismatch between the education sector and the market which all reports have mentioned as one of the major reasons for unemployment is distorting, as the gap is created by the kind of development approaches practiced based on a free market economy where the majority of people are excluded from the development process and marginalized including women who have no access to resources.

At the same time, it is important to note that in the last decade, education and in particular higher education have been co-modified and transformed into a consumer-oriented corporate network whose public interest values have been seriously challenged (Hill \& Kumar, 2008). Since the 1970s, it has been observed that the forces of market fundamentalism strip education of its public values, critical content, and civic responsibilities following its mission of creating new subjects are devoted to consumerism, risk-free relationships, and the destruction of the social state. It has been transformed and limited to instrumental goals committed almost exclusively to economic goals reflected in preparing students for the workforce. However, paradoxically, in practice, implementing neoliberal policies required special strategies and tools like: cutbacks in the public sector, closure of inefficient programs that do not directly meet business needs although promote 
critical thinking, use of computers, and distance learning where courses are packaged and delivered over internet (Tabb, 2001). Such policies have a contradictory goal to human development or sustainable development, as it results in expanding unemployment rather than finding new employment opportunities, and deteriorating quality of education. In view of this critique, an emphasis in the analysis should focus on the fact that public universities were established to promote independence of intellectual thought, to enable scholars to work outside the control of powerful vested interest groups, and be able to develop their critical thinking. If this is not reproduced and maintained, then education will lose its historical role and will become a commodity that is standardized and uniform with other education systems abstracted from the political and social reality, where agency and resistance will become obsolete and irrelevant in the face of qualities and principles of market economy, and more people are transformed to technocrats, bureaucrats, and consumers alienated from appropriate ideological and theoretical frameworks, hegemonizing and substituting critical knowledge, the only product that can produce the required democratic change and a more equal economic and social system that opens equal spaces for disadvantaged and marginalized individuals (Kuttab, 2014).

\section{Challenges of Environmental Sustainability and Food Security}

With accelerated population growth and urbanization and "wheat trap", the link between food security and environmental sustainability is becoming strongly pronounced. The Arab countries with $5 \%$ of the world's population import 30 million tons of grain representing $20 \%$ of the world's grain exports. This represents $60 \%$ of the region grain consumption (Erath Policy Institute, 2012). The Arab Human Development Report (AHDR) 2009 succeeded in highlighting the environment, resource pressures, and human security in the Arab countries. However, the issue will remain central to the development challenges of post-2015. As Zyadin (2013) rightly noted, the chronic water shortage in the Middle East North Africa (MENA) region is a perplexing issue, undoubtedly because various operational sectors, multi-institutions, and stakeholders are inextricably interconnected. In the light of climate variability and the unprecedented population growth rate, the per capita water resources and bio-capacity will continue plummeting and the demand-gap will seriously expand. Several studies draw the attention to the likely negative impact of global warming, but even if this predicted negative impact is overestimated, the ongoing process of desertification, deforestation, rapid urbanization, and declining trends of annual rainfall is impacting negatively not only MENA countries but also the international rivers on which some countries are almost dependent (Egypt and Iraq) (Retrieved from http://siteresources. worldbank.org/INTMNAREGTOPWATRES/Resources/Water_Sector_Brief--Fall2010.pdf). ${ }^{1}$ The decline in water storage of the transboundary basins will have a negative effect on water supply for all regions in the MENA. In the Eastern Mediterranean (Varis, 2007), the largest change, however, is a decrease in precipitation that occurs in area covering the Eastern Mediterranean, Turkey, Syria, Northern Iraq, Northeastern Iran, and Caucasus caused by the decrease in storm track activity over the Eastern Mediterranean. To the South of MENA, the challenges to the supply sources to the Nile Basin resulting for climatic variability; declining rainfall, deforestation, and other forms of land cover change are well documented (Awang, Forootan, Kuhn, Kusche, \& Heck, 2014; O. Yohannes \& K. Yohannes, 2012; Gebrehiwot, Bewket, Gärdenäs, \& Bishop, 2014;

\footnotetext{
1 The source of water varies from country to country. Some, like Egypt and Iraq, rely mostly on surface water from large international rivers. Others, like Yemen, Djibouti, and the Arab States of the Gulf Cooperation Council countries, depend almost entirely on groundwater and desalination, while others use a mixture of surface and groundwater. Most countries have mobilized almost all available surface water and many major rivers do not reach the ocean.
} 
Adar \& Check, 2011; Antonelli \& Sartori, 2015; Elnur, 2011). To the Western part of MENA desertification and degradation of ecosystems due to global warming, this paper will exacerbate the problem of water scarcity, particularly Morocco and Algeria (Zyadin, 2013). The disastrous impact of Qaddafi celebrated monument (the great manmade river) is being recently assessed in terms of historical loss of non-renewable resources where as in Saudi Arabia the priority should go to drinking water and basic human need (Bindra, Hamid, Abulifa, Al Reiani, \& Abdalla, 2014; Wheida \& Verhoeven, 2007).

There is a practical tendency to merge the two notions of food security and food self-sufficiency. The cost of pursuing the latter can be a recipe for wasteful use precious resources. The experience of Saudi-highly subsidized wheat production which led the underground water near depletion before the Saudi authorities backed off the unsustainable wheat production (Zyadin, 2013). Sudan's various versions of "breadbasket strategy" based on horizontal expansion and land-grabbing was another example of environmentally unsustainable food-sufficiency. Yet in post-2015, a major challenge phasing the region is how to build a wider regional cooperation that can accommodate a much higher level of sustainable food-sufficiency that can cultivate the diversities in ecological conditions in the region. Despite this long history of unfulfilled promises of failed regional attempts at the potential integration, an alternative scenario of a sustainable breadbasket strategy may be plausible and may enjoy far better chances of success, if the availability of financial resources both internally and regionally is optimally used in a context of a broadly-based "inclusive" alternative development strategy. In the case of Sudan, the rationale for such optimism is based on the great possibilities for productivity "catch up" for almost all major crops; the realization of the potential for integration of animal and crop production; and the actual surplus of irrigation water in addition to a huge potential hidden in the shift to more efficient irrigation system. However, beyond "naïve" optimism, any successful strategy for a new "bread basket" needs to be embedded in a more conducive political, socio-economic structure that facilitates its successful realization.

\section{Migratory Flows: Challenges of Integration, Brain Gain and Drain}

Migratory flows (receiving, sending, and both) are a major component of the making of the economies of the Arab region. While expatriates represent roughly 37\% of the GCC population on average, they constituted around 37\% of the population and "In Qatar, the UAE, and Kuwait, foreigners constituted a majority; in the United Arab Emirates, they accounted for over $80 \%$ of population. Only Oman and Saudi Arabia managed to maintain a relatively lower proportion of foreigners: about 20 and 27\%, respectively”. For the rest of the Arab countries labor export, Maghreb countries to the Europe and the rest to Arab oil-producing countries became a prominent source of income following oil price hikes of 1970s. Remittances share to GDP represents almost one fifth of the GDP in the historically diasporas-making countries like Lebanon, around $13 \%$ in Jordon but also a significant source of income for the rest of labour-export economies (Morocco 6\% and around 5\% for the Egypt, Tunisia, Sudan, Syria, and Yemen). Naturally all labour-exporting countries are venue for labour import as replacement. In post-2015 in the predominantly labour-import dependent economies of GCC states, a plethora of political, economic, cultural, and security challenges will acquire far more prominence in both political and development agendas as highlighted by the recent discourses on graduates unemployment crisis and the contestation between the profit-driven concerns of the private sector and the indigenization efforts of the states (Kapiszewsk, 2006).

For labour-export countries, the trend of declining, remittances, markets that gets saturated, as well as the ongoing global financial crisis may represent a serious development challenge in the short to medium terms. In 
addition, labour-export countries are witnessing labour inflows from lower income countries that are crowding out indigenous workers. In the long term, the issue of "Brain Drain" (in terms of quality not sheer numbers) will emerge as a serious challenge to the development process.

\section{Gender Equality and Women's Empowerment}

As a cross cutting issue, progress at level of gender equality and women's empowerment is dependent on improvement in other MDG goals, at the same time performance at the level of MDG goals can only be assessed in a gender perspective or else the analysis will be distorting and limited.

It is well known that the Arab region has witnessed significant advances on the level of women's status especially in health and education where progress has been comprehensive in all regions and for both genders. Nonetheless, measuring women's empowerment in the limited framework of Gender Empowerment Measure (GEM) reflected in formal political representation and enrollment in the labor force is not sufficient nor reflective or realistic to capture the real situation of women especially in the last decade, when they acted as the main shock absorbers for the grave structural economic changes and expanding poverty stricken shanty towns through promoting coping strategies, and in conflict zones, communities subjected to outside aggression like the occupied Palestinian territory.

At the same time, measuring women's empowerment using only quantitative indicators cannot capture the real meaning of women's empowerment which happens within their daily life experiences. The methods that they adopt to protect the household and support its resilience and survival, resisting the everyday violence in its public and domestic form, fighting the colonial occupation in occupied Palestinian territory (OPT), finding sources of income through informal economic projects or household activities, caring for family members in times of stress, or reaching formal and informal organizations for social assistance to manage the family's everyday's survival are all indicators for women's empowerment (Kuttab, 2010). Hence, a new look towards women's empowerment is more creative and realistic and is depicted from their own reality and their chosen strategies for everyday management of their household become a realistic indicator for measuring empowerment.

On another level, although women's share in wage employment in non-agricultural sector in the Arab region is the lowest in the world, acknowledging the overall structural obstacles that men and women face in terms of unemployment, the nature of labor markets that are gendered, economic reform adjustments based on recommendations to minimize the public sector, have affected women's ratio in non-agricultural employment (Khalidi, 2011). Furthermore, marginalizing the agricultural sector, which resulted in poverty and food insecurity in the different regions, has also affected the role of women in agricultural employment.

Additionally, the informal economic activities that have rescued the households in the face of collapse of the traditional breadwinner, the drought, and environmental changes can also represent an indicator measuring women's empowerment.

Although representation of women in formal political structures has not reached more than $10 \%$ even with the institutionalization of the quota system in some regions, the mismatch is between real everyday political and economic practice that enhances patriarchy in all its forms, especially in conflict zones, versus the liberal discourse adopted by different international conventions and agreements that call for gender equality. There are many steps to encourage women's participation in politics, but it can only happen in a holistic framework and a gradual process that links economic empowerment, cultural transformation in relation to stereotypes and 
traditional practices through an educational process that is critical and democratic.

Furthermore, empowerment cannot be attained from a technical view point. Enhancing economic empowerment through microfinance and ensuring education for all when quality of education and the curriculum is gender biased; teachers are the bearers of traditional ideas on gender roles; or appointing women in ministries or parliaments through quotas on a patronage basis when opposition democratic political parties have collapsed is not empowerment. Women's rights are part of human rights and not independent from it, hence a comprehensive process of empowerment to marginalized groups mainly women and youth can be the first step towards democratic transformation and empowerment. Exclusionary policies have left the majority of the population marginalized within the political and economic system and the real challenge to achieve the MDGs is by promoting an inward looking alternative development that could enhance democratic transformation and empower marginalized groups economically and politically represent the real challenge towards achieving the different MDGs in a timely manner.

\section{Challenges of the Post-Uprising Economies}

The post 2011, waive of uprising with its extremely divergent paths and outcomes represents a major challenge for the post-2015 MDGs. The challenges are common even in the case of relatively successful transition as in the case of Tunisia. Firstly, the structural inequalities that triggered various forms of uprisings and protests are still dominant in the economies of the countries that witnessed uprisings, in those which successfully suppressed it, as well as in those outmaneuvered protests by some temporary measures without addressing its root causes (Bahgat, 2015; Zoubir, 2015). Secondly, the post-uprising era of political instability and rising threats of extremist ideologies and violence represents a major challenge for post-2015 social and economic development. In extreme cases, the transition produced civil war situation or security deadlock (Libya, Syria, and Yemen). The security dilemma, however, may constitute a major threat to the economies heavily relying on external flows (tourism, remittances, etc.) as the typical case of both Egypt and Tunisia.

\section{Conclusions}

Three concepts, "poverty reduction", "participation", and "empowerment" have gained considerable importance in recent years in the language of mainstream development, as they are inter-related and structurally linked. There could be no empowerment without elimination or alleviation of poverty; participation in decision making to ensure a democratic participatory approach; or inclusion and collective as well as individual rights to ensure the right to decent work. In this context, the narratives of the MDGs should be understood, which were adopted in 2000, as they have been seen within a broader consensus and framework, reflecting a changing but cultivated narrative of buzzwords emphasizing these concepts. Focusing on these concepts, the MDGs provided different sets of objectives, one is to meet the challenges regarding the effectiveness of aid and agendas for greater coherence, while the other is a response to the moral authority and effectiveness of the global development audience, showing the commitment of the citizens of Northern countries participating around development issues to a previously unprecedented degree (Cornwall \& Brock, 2005). A guilt feeling is being substituted by lip service.

However, the issue of progress in achieving the MDGs can be monitored at different levels and scales (Vandemoortele, 2004), but their primary nature is one of composite measurability. Their narrative focuses on measuring change already set in motion, not on analysis of the forces that produce poverty. In doing so, the 
MDGs stimulate new discussions mainly about why they might not be met and what can be done about it which then becomes irrelevant and unable to produce a change (Cornwall \& Brock, 2005). Such analysis has its shortcomings or setbacks, as it does not address the real structural issues and reasons why MDGs were not achieved, but takes a compromising position, rather, a neutral and a historical position towards the problematic of development. Hence, such "buzzwords" have been normalized, bureaucratized, and instrumentalized through exercises of mainstreaming, goals, and targets at the global level representing the next step of accommodation with the global, and displacement from the specificities of the context.

Although a reference is made to MDGs in different policy documents, their usage has become decorative, as it only suggests some paths of change, while for the civil society organizations (CSOs) in the South, advocacy around the MDGs is considerably less clear. In certain instances, authors realized that the United Nation Development Programme (UNDP) or even the World Bank seeks to strengthen the CSO capacity in monitoring the MDGs, to extend beyond "their narrow role of social watchdog" (Vandemoortele, 2004, p. 2), reinforcing their experiences through financial assistance which has become an extension of the political landscape of bilateral donors' own backyards. Civil society actors are not the only ones asking why progress is on the MDGs, although feasible is not "on track". It seems that the time has come to put side by side two analyses from different sources, as they reveal the implicit and empty assumptions of the MDG narrative. The first, from within the UN, addresses the question "why are promises not being kept?" and suggests a way forward, including stronger partnership and deeper participation (Cornwall \& Brock, 2005). The second is what kind of meaning such recommendations have when they are applied to a particular place, or a particular context. Hence, as these words can have multiple meanings and measurements, maybe it is time to pay more attention to language, maybe it creates a new language in development that makes it more context-specific, relevant, and realistic, so that it can gain more meaning and become measurable.

At the same time, changing concepts to suit the context may be also critical as such concepts have been created in struggles for equality, social justice, and rights. If concepts maintain their meanings and they are not stripped from their original content, then participation for instance does not involve users as consumers, nor poor people are being empowered through privatization of services that were once basic rights, nor much more vital and relevant they would become to the struggles pursued by advocates and activists. Consider, too, what a difference might be made by more "clarity through specificity" (Cornwall \& Brock, 2005).

Terms and concepts are never neutral, they come to be given meaning as they are put to use in policies. These policies, in turn, influence those who work in development and how they impact people. Hence more attention should be given to content and meaning of development narrative as the changing situations and conditions of the region require more original revisiting of the development discourse and concepts used. Accurate, specific, relevant, and responsive are qualities that should describe the MDG narrative to become appropriate, effective, and measurable.

In the meantime, in such a historic moment driven by an urge for a change, there is a call by youth of the region for a new development model that ends the political economy of the rentier states, for an inclusive sustainable participatory development where economic growth is not based on a free market and can transform the economy from service oriented to a productive economy that generates real employment opportunities and decent work. At the same time, transitional governments should be pressured through a combined effort by international as well as civil society organizations to create a formal commitment to democratic transition and governance through the realization of political participation and freedom of speech. A comprehensive model 
that can give more space for social and gender equality, and economic growth that trickles down to development based on social justice and human dignity, where the citizen becomes the means and the end for development process.

\section{References}

Adar, K. G., \& Check, N. (2011). Cooperative diplomacy, regional stability and national interests: The Nile River and Riparian States. Retrieved from http://www.saiia.org.za

Ammar, H. (1996). University: Between mission and institutionalism: Studies on education and culture (in Arabic). Cairo: Arabic Studies Publishers.

Antonelli, M., \& Sartori, M. (2015). Unfolding the potential of the virtual water concept. What is still under debate? Environmental Science \& Policy, 50, 240-251.

Awange, J. L., Forootan, E., Kuhn, M., Kusche, J., \& Heck, B. (2014). Water shortage changes and climate variability within the Nile Basin between 2002 and 2011. Advances in Water Resources, 73, 1-15.

Bahgat, G. (2015). Egypt in the aftermath of the Arab spring: What lies ahead? Conflict Trends, 1, 3-9.

Bindra, S. P., Hamid, A., Abulifa, S., Al Reiani, H. S., \& Abdalla, H. K. (2014). Assessment of impacts on ground water resources in Libya and vulnerability to climate change. Scientific Bulletin of the "Petru Maior" University of Tîrgu Mureș, 10(2), 63-69.

Cornwall, A., \& Brock, K. (2005). "Poverty reduction", "participation" and "empowerment" in development policy (Overarching Concerns Program, Number 10).

Elnur, I. (2004). Differentiation in the educational systems, diasporas and reproduction of educated elites. In A. B. Hafaiedh and M. E. Jaziri (Eds.), Social science in the Arab World, Turkey and Iran: Determinants, state and potentials. Tunis: Center d'Etudes et de Recherches Economiques et Sociales.

Elnur, I. (2009). Contested Sudan: The political economy of war and reconstruction (Durham Modern Middle East and Islamic World series). London: Routledge.

Elnur, I. (2011). The changing hydraulics of conflict and cooperation in the Nile Basin: The demise of bilateralism. In S. Elmusa (Ed.), The burden of resources: Oil and water in the Gulf Region and the Nile Basin. Cairo: AUC Press.

Elnur, I. (2012). From political patronage to empowerment: A critique of subsidies' systems, anti-poverty policies and inequalities in rentier and quasi-rentiers regimes in the Arab World (Background paper for the Arab Human Development Report 2013, unpublished).

Elnur, I. (2013). The implosion of political patronage regimes in the Middle East. In D. Tschirgi, W. Kazziha, and S. McMahon (Eds.), Egypt's Tahrir revolution: Perspectives and prospects. Colorado, USA: Lynne Rienner Press.

Erath Policy Institute. (2012). Arab grain imports rising rapidly. Retrieved from www.earth-policy.org/data_highlights/2012/highlightd

European Training Foundation. (2010). Women and work: Limitations and potential in tourism and ICT: Egypt, Jordon and Tunisia (ETF working paper, November).

European Training Foundation. (2011). European training foundation: TORINO process: Evidence-based policy making for vocational education report, expand training (Working paper May 2011).

Gebrehiwot, S. G., Bewket, W., Gärdenäs, A. I., \& Bishop, K. (2014). Forest cover change over four decades in the Blue Nile Basin, Ethiopia: Comparison of three watersheds. Regional Environmental Change, 14(1), 253-266.

Hilal, J., Kuttab, E., \& Abdel, M. A. (2015). Palestinian review in international human development report 2014 (Development Studies Center, Birzeit University, Palestine).

Hill, D., \& Kumar, R. (2008). A review of "global neo-liberalizm and education and its consequences". New York: Routledge.

Ibrahim, S. (2000). Arab social science research in the 1990s \& beyond: Issues, trends and policies. In E. Rached and D. Craissati (Eds.), Research for development in the Middle East \& North Africa. Ottawa: IDRC.

Kallis, G., \& Zografos, C. (2013). Hydro-climatic change, conflict and security. Climatic Change, 123(1), 69-82.

Kapiszewsk, A. (2006). Arab versus Asian migrant workers in the GCC countries (Population Division Department of Economic and Social Affairs, United Nations Secretariat Beirut).

Khalidi, S. (2011). Neoliberalism as liberation: The statehood program and the remaking of the Palestinian national movement. Journal of Palestine Studies, 9(2), 6-25. 
Kuttab, E. (2010). Empowerment as resistance: Conceptualizing Palestinian women's empowerment. Development, 53(2), 247-253.

Kuttab, E. (2014). Education under occupation: A gender perspective in dangerous decade: The second gender profile of the occupied west bank and Gaza (2000-2010) (Institute of Women Studies, Birzeit University, Palestine).

Tabb, W. (2001). Globalization and education as a commodity. New York: Clarion Books.

UNESCO. (2010). Education for all: Global monitoring report 2008. Retrieved from http://www.eg.undp.org/content/undp/en/home/librarypage/hdr.html

Vandemoortele, J. (2004). Are the millennium development goals feasible? In R. Black and H. White (Eds.), Targeting development. London: Routledge.

Varis, O. (2007). Right to water: The millennium development goals and water in the MENA. International Journal of Water Resources Development, 23(2), 243-266.

Wheida, E., \& Verhoeven, R. (2007). The role of "virtual water" in the water resources management of the Libyan Jamahiriya. Desalination, 205(1), 312-316.

World Bank. (2007). The road not travelled: Education reform in the Middle East and North Africa. Retrieved from http://web.worldbank.org/WBSITE/EXTERNAL/COUNTRIES/MENAEXT/0,,contentMDK:21617643 pagePK:146736 :2 26340 theSitePK:256299,00.html

World Bank. (2010). Water brief. $\quad$ sector Retrieved from http://siteresources.worldbank.org/INTMNAREGTOPWATRES/Resources/Water_Sector_Brief--Fall2010.pdf

Yohannes, O., \& Yohannes, K. (2012). Turmoil in the Nile River Basin: Back to the future. Journal of Asian and African Studies, 48(2), 195-208.

Zoubir, Y. H. (2015). The democratic transition in Tunisia: A success story in the making. Conflict Trends, 1, 10-17.

Zyadin, A. (2013). Water shortage in MENA region: An interdisciplinary overview and a suite of practical solutions. Journal of Water Resource and Protection, 5, 49-58. 